\title{
Primary tuberculosis of cystic duct lymph node
}

\author{
Aamir Ghazanfar, ${ }^{1}$ Afifa Asghar, ${ }^{1}$ Naqeeb Ullah Khan, ${ }^{2}$ Iram Hassan ${ }^{1}$
}

'Department of General Surgery, KRL Hospital, Islamabad,

Pakistan

${ }^{2}$ Department of Epidemiology, KRL Hospital, Islamabad, Pakistan

\section{Correspondence to} Dr Naqeeb Ullah Khan, naqeeb16@yahoo.com

Accepted 29 May 2017 CrossMark

To cite: Ghazanfar A, Asghar A, Khan NU, et al. BMJ Case Rep Published Online First: [please include Day Month Year]. doi:10.1136/bcr-2016218804

\section{SUMMARY}

Tuberculosis (TC) is very common and significant cause of morbidity and mortality worldwide. Isolated cystic duct lymph node TC cases without involvement of gallbladder are exceedingly rare. It is difficult to diagnose preoperatively because of lack of characteristic signs and symptoms of TC. We report a man aged 45 years who presented with right upper abdominal pain since 1 week. It was associated with nausea and postprandial fullness. There was no evidence of jaundice and lymphadenopathy. Abdominal examination showed moderate right upper quadrant tenderness with positive Murphy's sign and splenomegaly but no signs of peritonism. Abdomen ultrasound revealed sludge in gallbladder, dilated pancreatic duct, coarse exotexture of liver, splenomegaly and no lymphadenopathy. He underwent laparoscopic cholecystectomy; histological report showed chronic caseating granulomatous lymphadenitis with Langhans type of giant cells in lymph node near cystic duct with chronic cholecystitis of gallbladder. Standard antituberculosis therapy was given for 12 months.

\section{BACKGROUND}

Tuberculosis (TC) is very common, hepatobiliary tuberculosis (HBT) is a very rare disease and constitutes $1 \%$ of all abdominal TC cases. ${ }^{1}$ Isolated cystic duct lymph node TC has not been classified anywhere because so far very few number of cases have been reported. ${ }^{1}$ This case is similar to De Melo et al's and Sali et al's study where patient presented with biliary colic for which laparoscopic cholecystectomy was done and cystic duct lymph node TC without gallbladder involvement was diagnosed incidentally on histopathology. ${ }^{23}$

\section{CASE PRESENTATION}

A man aged 45 years presented with right upper quadrant abdominal pain, severe in intensity, non-radiating, associated with nausea and postprandial fullness since 1 week. There were no symptoms of fever, cough, haemoptysis, anorexia, weight loss, night sweats, vomiting, diarrhoea, dysuria, haematemesis and melaena. He had no history of headache and neck stiffness. He was non-diabetic, non-smoker and had no history of alcohol intake. He had history of exposure to a patient with TC but denied any contact with pets and ingestion of non-pasteurised milk. He had been previously admitted twice with same complaints in some other hospitals prior to this hospitalisation, where he was managed conservatively and not investigated in detail. He had been diagnosed hepatitis C, 2 years back, for which he was treated with interferon therapy. Recent PCR for hepatitis C virus (HCV) RNA was found negative.

On examination, pulse rate was 80 per minute, blood pressure was $120 / 70 \mathrm{~mm} \mathrm{Hg}$ and temperature was $98.6^{\circ} \mathrm{F}$. There was no evidence of jaundice and lymphadenopathy. Abdominal examination showed moderate right upper quadrant tenderness with positive Murphy's sign, splenomegaly $(15 \mathrm{~cm}$ size, smooth surface, non-tender and firm consistency) and no signs of peritonism. Cardiopulmonary and remainder of systemic examination was unremarkable.

\section{INVESTIGATIONS}

Complete blood picture showed haemoglobin of $14.4 \mathrm{~g} / \mathrm{dL}$ with normal white cells and platelet count of $63 \times 10^{9} /$ L. Serum amylase was 94 with normal level of liver and renal function tests and coagulation profile. His chest $\mathrm{x}$-ray, lipid profile, ferritin and iron levels were normal, and serology for hepatitis $\mathrm{B}$ was negative.

Abdomen ultrasound showed a coarse exotexture of liver with no focal lesion or intrahepatic cholestasis. Spleen was $15 \mathrm{~cm}$ in size with no focal lesion. Pancreas was of normal size with mildly prominent pancreatic duct. Gallbladder contained sludge with normal calibre of common bile duct. Portal vein was of normal calibre with no abdominal lymphadenopathy.

\section{DIFFERENTIAL DIAGNOSIS}

Differentials of primary cystic duct lymph node TC are HBT, acute cholecystitis and acute pancreatitis.

\section{TREATMENT}

Patient was initially treated conservatively for 5 days. On sixth postadmission day, he underwent laparoscopic cholecystectomy due to persistent symptoms, failed to respond on conservative treatment. Peroperative findings showed coarse nodular liver, likely secondary to hepatitis $\mathrm{C}$, distended gallbladder with sludge, splenomegaly and no other abnormal findings as shown in figure 1. Cholecystectomy was done, and gallbladder specimen was sent for routine histological examination.

\section{OUTCOME AND FOLLOW-UP}

Patient remained hospitalised for 8 days and was discharged 2 days after laparoscopic cholecystectomy. Histological examination of specimen surprisingly showed chronic caseating granulomatous lymphadenitis with Langhans type of giant cells in lymph node near cystic duct and chronic 


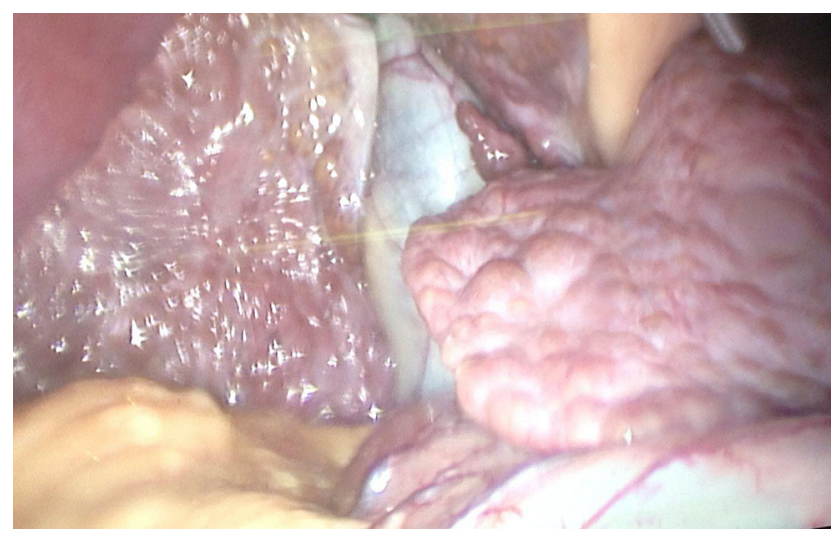

Figure 1 Liver cirrhosis and distended gallbladder with sludge.

cholecystitis of gallbladder as shown in figures 2 and 3. CT scan of abdomen done 10 days after the operation showed no abdominal lymphadenopathy or evidence of any other abdominal pathology. Three sputum smears for acid fast bacillus and tuberculin skin test were negative.

Standard directly observed oral therapy for treatment of TC started with isoniazid $300 \mathrm{mg}$, rifampacin $600 \mathrm{mg}$, pyrazinamide $1600 \mathrm{mg}$ and ethambutol $1200 \mathrm{mg}$, daily for 2 months in initiation phase. Isoniazid $300 \mathrm{mg}$ and rifampicin $600 \mathrm{mg}$ given for further 10 months in continuation phase. He is advised for follow-up twice weekly initially for 2 months and then monthly for 1 year in order to determine the effectiveness and toxicity of treatment.

Complete blood count, liver enzymes, serum uric acid, serum creatinine, visual acuity and perception of red-green colour testing advised in follow-up visits. He had no complications of treatment. CT of abdomen advised at the last month of therapy. It showed no evidence of abdominal lymphadenopathy and coarse exotexture of liver and splenomegaly as before.

$\mathrm{He}$ is also advised follow-up with serum alpha fetoprotein and abdomen ultrasound every 6 months because of significant risk of hepatocellular carcinoma secondary to liver cirrhosis.

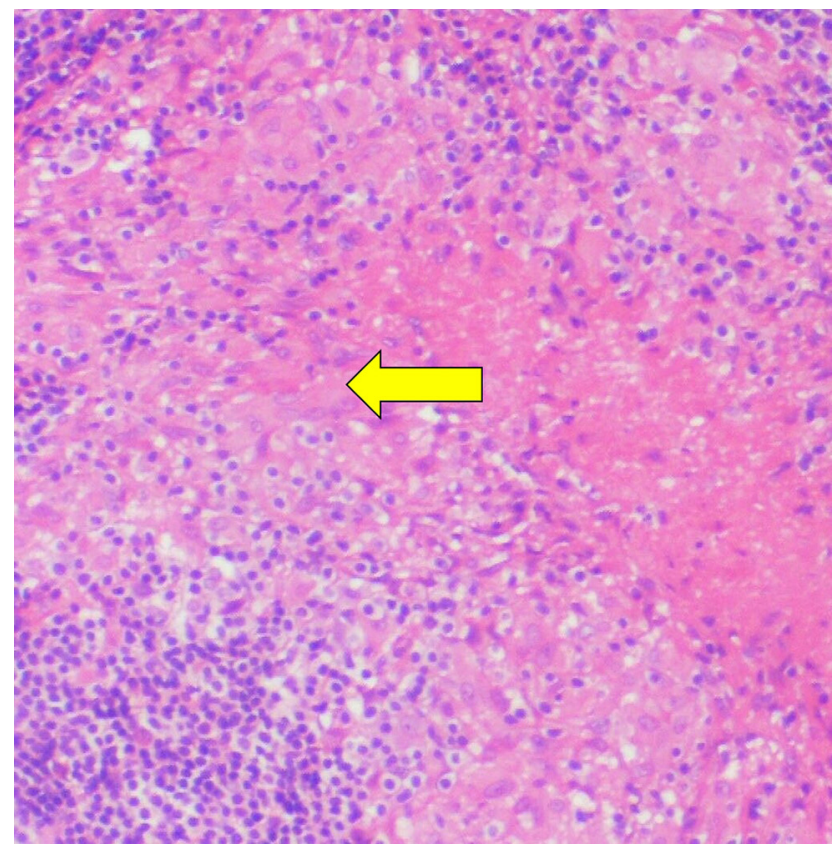

Figure 2 Section of lymph node showing chronic caseating granulomatous lymphadenitis with Langhans type of giant cell.

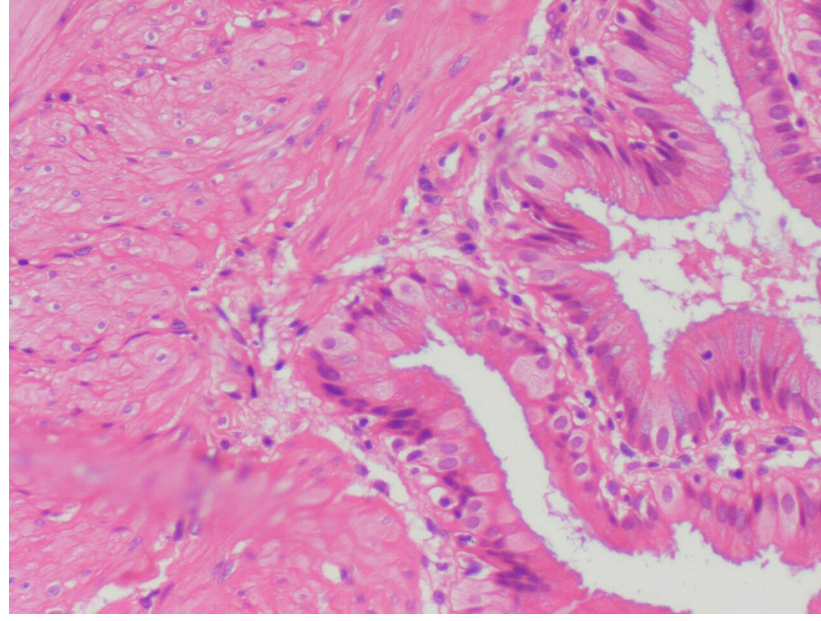

Figure 3 Section of gallbladder showing mononuclear inflammatory infiltration of mucosa with variable degree of fibrosis.

\section{DISCUSSION}

TC is a widespread disease worldwide. ${ }^{4}$ Twenty per cent to $30 \%$ of world population is infected with Mycobacterium tuberculosis. It is a significant cause of morbidity and mortality worldwide. ${ }^{5}$ Pakistan currently ranks fifth highest burden of TC among countries all over the world with the fourth highest burden of drug-resistant TC. It is estimated that in around 180 million population, annual incidence of TC is 231/100 000 and 420000 new cases of TB reported annually in Pakistan. ${ }^{6}$ Prevalence of TC in developing countries is approximately $95 \% .^{7}$ According to WHO guideline, $47.28 \%$ cases of extrapulmonary tuberculosis (EPTB) have been reported among all patients with TC worldwide. $^{48}$ A percentage of $3.5 \%$ of all patients with EPTB have abdominal TC. ${ }^{79}$

HBT is very uncommon. Hepatic TC is classified as focal, tubular, miliary or granulomatous TC. ${ }^{10}$ TC of isolated cystic duct lymph node has not been classified anywhere because very few number of cases have been reported. ${ }^{111}$

Causative agent of TC is M. tuberculosis. It is aerobic, obligate intracellular and non-spore forming acid-fast bacillus. It has very slow replication rate. Although pulmonary TC is most common, TC can affect other organs of body leading to EPTB. TC may present with non-specific signs and symptoms such as fever, fatigue, night sweats and weight loss or related to organ affected. However, one-fourth of M. tuberculosis culture positive pulmonary TC cases are asymptomatic. ${ }^{12}$

In Amarapurkar et al' s study, it is revealed that prevalence of hepatic TC as a result of disseminated TC is 50\%-80\%, but localised HBT is uncommon. Out of 242 patients, HBT was detected in 38 patients. ${ }^{13}$

In another study, 14 out of 1888 patients were diagnosed with HBT. $^{10}$

Ninety per cent of cases with gallbladder TC have gallstones. ${ }^{14}{ }^{15}$ Cystic duct lymph node TC without affecting gallbladder is exceedingly rare. If disease is not treated promptly, it will spread to biliary tract. It may lead to biliary stricture, bilioma and infected abscess. ${ }^{16}$ Pathogenesis of biliary TC is either hematogeneous spread, biliary contamination via swallowed sputum containing bacteria or direct extension from adjacent structures. $^{23}$

Gallbladder TC is very rare because high alkalinity of bile causes resistance to growth of $M$. tuberculosis. Most of the reported cases of gallbladder TC are associated with gall stones, but it can also be seen in absence of gall stones. ${ }^{17} 18$ 
Diagnosis of EPTB is a challenge. Preoperative diagnosis of isolated cystic duct lymph node TC is very difficult especially in cases with any other pathology. Criteria for the diagnosis of isolated cystic duct lymph node TC is established when at least one of the following is present:

- Histological examination of specimen shows caseating granulomatous lymphadenitis with Langhans type of giant cell in lymph node.

- Acid fast bacilli demonstration on histological specimen.

- M. tuberculosis culture is positive.

- PCR for M. tuberculosis is positive. ${ }^{3}$

- Conventional anti-TC quadruple therapy is recommended, and prognosis of disease is good with complete treatment.

In this case ultrasound and peroperative finding showed liver cirrhosis most likely secondary to hepatitis C. Cirrhosis of liver is the 12th leading cause of death worldwide. In Pakistan, most common causes of liver cirrhosis are fatty liver and hepatitis C. ${ }^{19}$ Fatty liver disease can be alcoholic or non-alcoholic liver disease. Non-alcoholic fatty liver disease is associated with high cholesterol level, type 2 diabetes mellitus, obesity, insulin resistance and drug toxicity. In western countries, prevalence of non-alcoholic liver disease is about 30 per cent, mainly associated with sedentary lifestyles and high fat intake. ${ }^{20}$

Spontaneous resolution of chronic hepatitis C is rare. Most patients with chronic hepatitis $\mathrm{C}$ remain asymptomatic for a long period of time. In hepatitis $\mathrm{C}$ infection, risk of development of cirrhosis of liver is after approximately 30 years. Risk of hepatocellular carcinoma increases with the degree of fibrosis of liver. ${ }^{21}$ Fifty-seven per cent of hepatic cirrhosis is secondary to hepatitis B virus (HBV) (30\%) or HCV (27\%). Globally, 78\% hepatocellular carcinoma is caused by HBV $(53 \%)$ or HCV $(25 \%) .{ }^{22}$

Biliary sludge may be associated with biliary colic, acute cholecystitis or acute pancreatitis. It is generally diagnosed on abdominal ultrasound. Most useful diagnostic tests are abdomen ultrasound and hepatobiliary scintigraphy. ${ }^{23}$ In a study done by Mirvis et al, 56 patients with acute acalculous cholecystitis were

\section{Learning points}

- Tuberculous involvement of isolated cystic duct lymph node is exceedingly rare. It is difficult to diagnose preoperatively because of the rarity of disease and absence of characteristic signs and symptoms of tuberculosis (TC).

- Histological examination is necessary for diagnosis and if caseating granulomatous lymphadenitis with Langhans type of giant cells in lymph node near cystic duct is confirmed, then standard anti-TC therapy should be given for 1 year to avoid further complications.

- Accurate preoperative diagnosis is difficult to establish, and literature has shown that most of the cases are diagnosed incidentally after histological examination of gallbladder specimen postcholecystectomy.

- Routine histological examination of gallbladder along with lymph node near cystic duct should be made a standard practice. evaluated. Ultrasound and CT showed sensitivity of $92 \%$ and $100 \%$, respectively, and specificity of $96 \%$ and $100 \%$, respectively. Ultrasound is less expensive and safe because it has no radiation hazards. ${ }^{24}$

Contributors AG operated the case and selected it for publication. He also contributed in the drafting and final revision of the document. AA wrote the abstract, case presentation, investigations and treatment sections of this article. NUK is a consultant epidemiologist who critically reviewed the whole manuscript, edited and drafted the manuscript again and gave a final touch to the report and made it ready for publication. IH did extensive literature search for this case report. She also wrote the Discussion section and provided the references for the article.

Competing interests None declared.

Patient consent Obtained.

Provenance and peer review Not commissioned; externally peer reviewed. (c) BMJ Publishing Group Ltd (unless otherwise stated in the text of the article) 2017. All rights reserved. No commercial use is permitted unless otherwise expressly granted.

\section{REFERENCES}

1 Goyal SC, Goyal R, Malhotra V, et al. Tuberculosis of the gall bladder. Indian J Gastroenterol 1998;17:108

2 de Melo VA, de Melo GB, Silva RL, et al. Tuberculosis of the cystic duct lymph node. Braz J Infect Dis 2004;8:112-4.

3 Sali G, Ali I, Sethi G, et al. Incidental cystic duct lymph node tuberculosis. Int I Case Rep Imag 2013;4:337.

4 Cagatay AA, Caliskan Y, Aksoz S, et al. Extrapulmonary tuberculosis in immunocompetent adults. Scand J Infect Dis 2004;36:799-806.

5 Sidhu DS, Singh M, Jindal RK, et al. Isolated cystic duct lymph node tuberculosis. $J$ Indian Med Assoc 2007; 105:460-8.

6 National TB control programme Pakistan. http://103.31.80.214:8080/apex/ $f ? p=102: 101$

7 Chaudhary P. Hepatobiliary tuberculosis. Ann Gastroenterol 2014;27:207.

8 Pestana E, Telo L, Gomes MJ, et al. [Extrapulmonary tuberculosis]. Acta Med Port 1993:6:175-80

9 Sharma SK, Mohan A. Extrapulmonary tuberculosis. Indian J Med Res 2004; 120:316-53

10 Chong VH, Lim KS. Hepatobiliary tuberculosis. Singapore Med J 2010;51:744-51.

11 Saluja SS, Ray S, Pal S, et al. Hepatobiliary and pancreatic tuberculosis: a two decade experience. BMC Surg 2007;7:10.

12 Karaosmanoglu AD, Onur MR, Sahani DV, et al. Indian Journal of Pathology and Microbiology 2008;51:175.

13 Amarapurkar DN, Patel ND, Amarapurkar AD. Hepatobiliary tuberculosis in western India. Indian J Pathol Microbiol 2008;51:175.

14 Bergdahl L, Boquist L. Tuberculosis of the gall-bladder. Br J Surg 1972;59:289-92.

15 Ziarek S, Deddouche M, Zoubir Y, et al. Tuberculosis de la vesicule biliaire. A Propos de trois cas. Med Chir Dig 1975;4:219-22.

16 Gupta NM, Khaitan A, Singh V, et al. Isolated gallbladder tuberculosis with postoperative biliary fistula. Endoscopy 1998;30:S 73-S 74

17 Cheddie S, Bisttey T, Singh B. Isolated tuberculosis of gallbladder. Int J Surg 2012;28

18 Lardner A. The effects of extracellular pH on immune function. J Leukoc Biol 2001;69:522-30.

19 Ali I, Khan JZ, Khan AU, et al. Pharmacotherapy evaluation ofdiabetic patients in ward of General Medicine, Northwest General Hospital \&Research Centre, A Case Study from Khyber Pakhtunkhwa, Pakistan. Pharmacologyonline 2015:1:104-208.

20 Wruck W, Graffmann N, Kawala MA, et al. Concise Review: current status and future directions on Research Related to Nonalcoholic Fatty liver disease. Stem Cells 2017;35:89-96.

21 Yoshida H, Shiratori Y, Moriyama M, et al. Interferon therapy reduces the risk for Hepatocellular Carcinoma: national Surveillance Program of Cirrhotic and Noncirrhotic patients with Chronic Hepatitis C in Japan. Ann Intern Med 1999; 131:174.

22 Perz JF, Armstrong GL, Farrington LA, et al. The contributions of hepatitis B virus and hepatitis C virus infections to cirrhosis and primary liver Cancer worldwide. J Hepatol 2006;45:529-38.

23 CW K, Lee SP. Biliary sludge and cholecystitis. Best Pract Res Clin Gastroenterol 2003; 17:383-96.

24 Mirvis SE, Vainright JR, Nelson AW, et al. The diagnosis of acute acalculous cholecystitis: a comparison of sonography, scintigraphy, and CT. AJR Am J Roentgenol 1986;147:1171-5. 
Rare disease

Copyright 2017 BMJ Publishing Group. All rights reserved. For permission to reuse any of this content visit http://group.bmj.com/group/rights-licensing/permissions.

BMJ Case Report Fellows may re-use this article for personal use and teaching without any further permission.

Become a Fellow of BMJ Case Reports today and you can:

- Submit as many cases as you like

- Enjoy fast sympathetic peer review and rapid publication of accepted articles

Access all the published articles

- Re-use any of the published material for personal use and teaching without further permission

For information on Institutional Fellowships contact consortiasales@bmjgroup.com

Visit casereports.bmj.com for more articles like this and to become a Fellow 